\title{
Effect of Antimicrobial Substances on the Ability of the Mysid Shrimp Mysis stenolepis to Digest Cellulose
}

\author{
P. F. Wainwright* and K. H. Mann** \\ Department of Biology, Dalhousie University, Halifax, Nova Scotia, Canada B3H 4J1
}

\begin{abstract}
The ability of Mysis stenolepis to digest cellulose was investigated by means of 4 interrelated experiments. The first experiment confirmed earlier findings that ${ }^{14} \mathrm{C}$ is rapidly assimilated from labelled cellulose. The second showed that this ability was lost when the mysids were exposed for $24 \mathrm{~h}$ to antimicrobial substances. The third revealed that the ability to digest cellulose was restored when the sterile mysids were fed freshly ground guts of normal mysids. The fourth showed that previous conditioning with a diet of cellulose led to higher levels of uptake than conditioning with a diet of protein.
\end{abstract}

\section{INTRODUCTION}

There is now considerable evidence that in many situations aquatic macrophytes have chemical defences against hervivores; that they progressively lose those defences as they die and are colonized by bacteria and fungi; that detritus-feeding invertebrates obtain most of their nutrition by digesting the microorganisms. Well, documented recent examples are Cundell et al. (1979) working with mangrove leaves and Briggs et al. (1979) working with seaweed. The ecological consequences of such a mechanism are that transfer of energy and materials from macrophytes to invertebrates requires at least one intermediate microorganismal step, with the associated losses during transfer. More recently, interest has been aroused in the possibility that some aquatic invertebrates are able to digest cellulose and might derive substantial nutrition from the structural materials of macrophyte detritus (Wildish and Poole, 1970; Halcrow, 1971; Elyakova, 1972; Monk, 1977; Fong and Mann, 1980). Foulds and Mann (1978) compared the uptake of ${ }^{14} \mathrm{C}$ from sterile and non-sterile labelled cellulose, and

\footnotetext{
- Present address: Environmental Protection Service, P.O. Box 370, Yellowknife, N.W.T., Canada X1A 2N3

- Present address: Marine Ecology Laboratory, Bedford Institute of Oceanography, Dartmouth, N.S., Canada B2Y 4A2
}

were surprised to find an apparently rapid and efficient uptake of the label from sterile cellulose.

This paper records a repetition of the Foulds and Mann (1978) experiment, and goes on to investigate whether the ability to digest cellulose is affected by treatment with antimicrobial substances and by various dietary pre-treatments.

\section{MATERIALS AND METHODS}

Mysis stenolepis were collected in the vicinity of Troop Island, St. Margaret's Bay, Nova Scotia $\left(44^{\circ} 35^{\prime} 12^{\prime \prime} \mathrm{N}, 63^{\circ} 56^{\prime} 00^{\prime \prime} \mathrm{W}\right.$ ) from eelgrass beds (Zostera marina) growing at depths of 5 to $10 \mathrm{~m}$. They were obtained by attaching a plankton net to a diver-operated underwater sled, towed behind a small boat. The diver steered the net so as to skim the tops of the eelgrass plants. In this way, large numbers of $M$. stenolepis were collected in good condition. They were held in the laboratory in running seawater at ambient temperatures (approximately $4{ }^{\circ} \mathrm{C}$ ) with an abundant supply of eelgrass detritus until required for use.

The experimental design was based on previous work by Foulds (1977), Wainwright (1977), and Foulds and Mann (1978). It consisted of 4 experiments run simultaneously, but these were integrated to form 1 
large experiment. The objectives of the 4 experiments are given first, and the plan of the integrated experiment follows.

\section{Assimilation of Cellulose}

The first experiment was designed to confirm the findings of Foulds and Mann (1978) that Mysis stenolepis assimilates cellulose. Healthy mysids were starved for $24 \mathrm{~h}$ in seawater filtered through a $1.2 \mu \mathrm{m}$ mesh. They were then presented with a suspension of ${ }^{14} \mathrm{C}$ Iabelled cellulose for $30 \mathrm{~min}$. Next they were transferred to a suspension of natural unlabelled detritus and allowed to feed for $3 \mathrm{~h}$, during which time they cleared their guts several times over. The mysids were then frozen on dry ice and held until ready for assay. After thawing, the guts were separated from other body tissue and the 2 fractions assayed for ${ }^{14} \mathrm{C}$ uptake. Controls consisted of mysids on which all these procedures had been carried out, but before being placed in labelled cellulose suspension they were killed by gently squeezing the heads with forceps.

\section{Effect of Antimicrobial Substances}

This experiment was designed to test the effect of antimicrobial substances on the mysids' ability to take up labelled cellulose. The antimicrobial solution consisted of $2.25 \mathrm{~g}$ streptomycin sulphate, $11.2 \mathrm{~g}$ penicillin $\mathrm{G}$ and $25 \mathrm{~g}$ Fungizone ${ }^{*}$ per litre of $1.2 \mu \mathrm{m}$-filtered seawater. The mysids were held in the antimicrobial solution for $24 \mathrm{~h}$, starved in filtered seawater for $24 \mathrm{~h}$, then exposed to ${ }^{14} \mathrm{C}$ cellulose suspension and treated as in the previous experiment. For convenience of description animals treated in this way will be described as 'sterile'. The effectiveness of the procedure was checked in pilot experiments by plate counts and direct microscopic examination.

\section{Effect of Reintroducing Microbes into the Guts of Mysids}

Two sets of mysids were treated with antimicrobial solution for $24 \mathrm{~h}$, transferred to clean water, then allowed to feed on either homogenized fresh mysid guts or on natural eelgrass detritus, for $24 \mathrm{~h}$. It was thought that if the digestion of cellulose was made possible by a gut flora, and if the antimicrobial solution suppressed this gut flora, it might be possible to restore the ability to digest cellulose by allowing the mysids to feed on natural sources of microbes.

\footnotetext{
- Registered trade mark
}

After the special treatment described above, the mysids were starved and then tested for their ability to digest cellulose, in the usual way.

\section{The Effect of Previous Diet on Ability to Digest Cellulose}

Since mysids are omnivorous and can be maintained in healthy condition in the laboratory for long periods while feeding on either detritus or on animal food, it was thought worthwhile to investigate whether differing diets predisposed these animals to digest cellulose with differing efficiencies. Before measurements of cellulose assimilation were made in any of the previous experiment, the mysids were divided into 2 lots and fed for 72 h on either sterile raw cellulose or sterile chopped Crangon sp. The experiments were then run in duplicate with mysids from the 2 batches.

\section{Integrated Experimental Procedure}

All mysids used in the experiments were of the same age class and of approximately the same weight. All

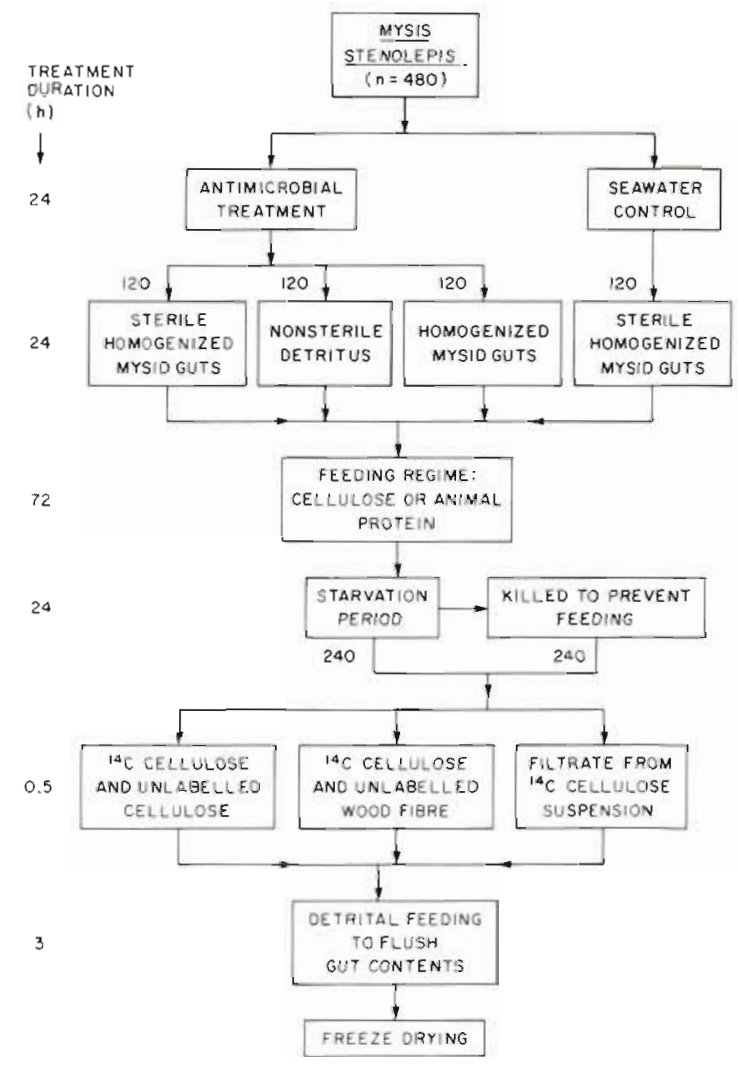

Fig. 1. Flow chart summarizing design of ${ }^{14} \mathrm{C}$ cellulose assimilation experiment 
containers used for the experiments were sterilized by repeated steam autoclaving, as was the seawater used in experiments with antimicrobial treatments. When mysids were exposed to food, their feeding activity was checked by observing the movement of food along the transparent gut. Certain treatments led to death of a proportion of the experimental animals thus leading to reduced numbers of replicates in the final results. Experimental containers were aerated with air that had passed a $0.22 \mu \mathrm{m}$ filter, and experiments were conducted at $4{ }^{\circ} \mathrm{C}$.

The integrated experiment (Fig. 1) began with 480 mysids, of which 120 were held in filtered seawater while the remainder were placed in 10-1 antimicrobial solution for $24 \mathrm{~h}$. At the end of that period four batches, each of 120 individuals, were segregated and used in subsequent experimental procedures. Two batches of sterilized mysids were reinoculated by giving them non-sterile food: non-sterile detritus to one batch and homogenized mysid guts to the other. Meanwhile, the third group of sterile mysids and the non-sterile group were offered only a suspension of sterile homogenized mysid guts.

At this point, each of the 4 groups was split in 2, so that 60 individuals could be conditioned for $72 \mathrm{~h}$ on a diet of sterile cellulose, while the other 60 received sterilized chopped Crangon sp. Next, each of the 8 batches was transferred to $4 \mathrm{l}$ of sterile filtered seawater and starved for $24 \mathrm{~h}$.

From this time onwards each batch of 60 mysids was treated in an identical manner. The standard treatment was as follows: Three kinds of ${ }^{14} \mathrm{C}$ cellulose suspension were prepared. The first was $600 \mathrm{ml}$ of filtered seawater containing $2 \mathrm{~g}$ of a mixture of 1 part of ICN Radiochemicals' ${ }^{14} \mathrm{C} \alpha$-cellulose of known specific activity with 9 parts of Sigma Chemical's unlabelled $\alpha$ cellulose. The second suspension had wood fibre instead of unlabelled cellulose. All particles in the suspension were in the range 20 to $800 \mu \mathrm{m}$. The third suspension was prepared in the same way as the first, but was then passed through a $1.2-\mu \mathrm{m}$ filter, so that the mysids were exposed only to the filtered liquid. For each kind of cellulose suspension an experiment was run with 10 living mysids and a control was run with 10 individuals killed by pinching their head. The mysids were exposed to the suspension for $30 \mathrm{~min}$, rinsed, then transferred to $600 \mathrm{ml}$ of sterile seawater with natural detritus to allow them to clear their guts. After $3 \mathrm{~h}$ they were collected from the jars and frozen immediately on dry ice.

To determine the assimilation of ${ }^{14} \mathrm{C}$ label the frozen mysids were individually thawed and the guts separated from the remaining tissues as in Foulds and Mann (1978). The tissues were dried at $38^{\circ} \mathrm{C}$ to constant weight, placed in scintillation vials, digested with $3 \mathrm{ml}$ Protosol ${ }^{\circ}$ for $72 \mathrm{~h}$ at $40^{\circ} \mathrm{C}$, then counted in $10 \mathrm{ml}$ Aquasol ${ }^{\circ}$.

To check recovery of counts, 5 - $\mathrm{ml}$ samples were taken from the liquid in which the mysids flushed their guts, and from the cellulose suspensions before and after feeding. The soluble and particulate ${ }^{14} \mathrm{C}$ was measured by scintillation counting in $10 \mathrm{ml}$ Aquasol* . All results were calculated from the mean of triplicate 10-min counts on a Packard model 3690 scintillation counter, corrected for quenching by the addition of an internal standard $\left({ }^{14} \mathrm{C}\right.$ toluene of known activity). The resulting counts were expressed as dpm (mg dry $w t)^{-1}$.

\section{RESULTS}

The main features of the results are very clear (Table 1). Beginning with the non-sterile Mysis stenolepis, the findings of Foulds and Mann (1978) were confirmed. A large number of counts was found in the body tissues of mysids allowed to feed on a mixture of labelled and unlabelled cellulose, a slightly smaller number in those fed a mixture which included wood fibre, and negligible counts in mysids that had been exposed to the filtered liquid. Counts on the bodies of controls were less than $3 \%$ of the counts on the bodies of those feeding actively on suspensions of cellulose, and counts in the gut tissue were always much lower than counts in the body tissue. The effect of the previous diet was quite marked: individuals conditioned on cellulose had counts about $3^{1 / 2}$ times as high as those conditioned on protein. From these results we may conclude that labelled carbon was assimilated from cellulose, and that incorporation of the label into the body tissues was a function af active filter feeding and was not due to passive uptake by microorganisms on the body surface nor to uptake from solution.

Turning to the 'sterile' mysids, we see that exposure to antimicrobial solution markedly impaired their ability to take up labelled cellulose. In most cases the counts in the body tissue were not significantly different from those of dead control individuals. Inoculation by feeding with ground mysid tissue restored in a most dramatic fashion the ability to assimilate cellulose. Counts in the body were 80 to $90 \%$ of the level seen in mysids that had not been subjected to antimicrobial treatment. Inoculation by feeding with natural detritus resulted in a much smaller increase in uptake of labelled cellulose. Once again, the effect of previous diet was clear. The uptake by mysids conditioned on a protein diet was always lower than uptake by individuals conditioned on cellulose.

\footnotetext{
- Registered trade mark
} 
Table 1. Mysis stenolepis. Net ${ }^{14} \mathrm{C}$ assimilations, i.e. differences between experimentals and controls, expressed as dpm (mg dry $w t)^{-1}$ by body (bold type) and gut (italicized) tissue fractions of individuals subjected to the 4 major treatments, and to prior feeding regimes of cellulose $(A)$ and animal protein $(B)$. Values are means \pm 1 standard deviation

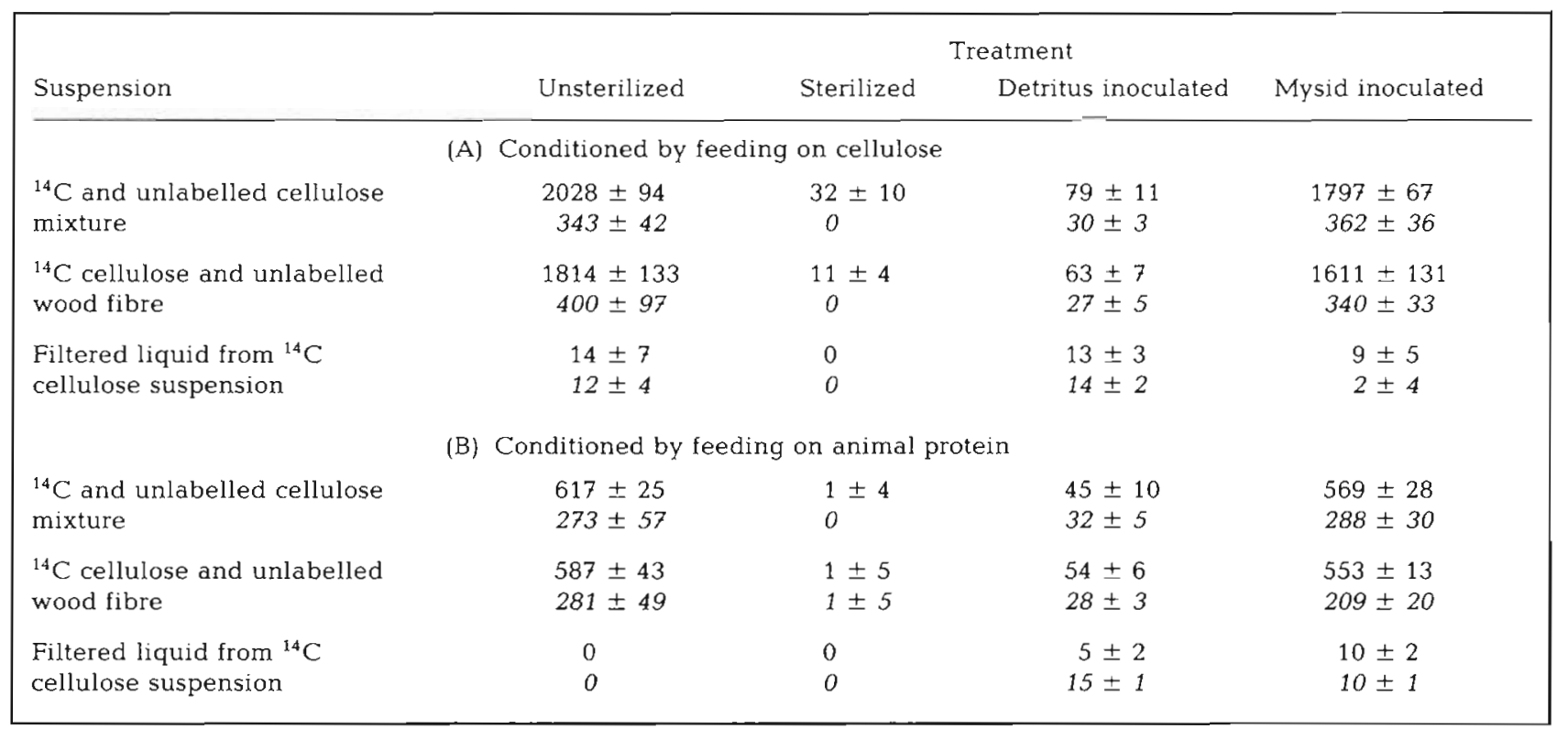

The reason for adding unlabelled wood fibre to the suspension was to see whether the presence of naturally occurring substances such as tars, resins or phenols would inhibit feeding activity. A small reduction in ${ }^{14} \mathrm{C}$ uptake was detected in every experiment except one, but the difference was not statistically significant in all cases.

When a check was made on the recovery of counts, it was found that the subsampling procedure used to estimate total counts in the cellulose suspension before and after feeding was not sufficiently intensive to give reliable estimates. In almost $30 \%$ of the cases the estimated counts after feeding were slightly higher than before feeding. In general, however, there were no unexplained losses of label, and in most experiments the budget for ${ }^{14} \mathrm{C}$ label could be balanced within $10 \%$ or less. Perhaps the most useful check on experimental procedure was the variance on total counts in the mysids. In most experiments, with up to 10 replicates, the coefficient of variation was less than $10 \%$.

\section{DISCUSSION}

The results obtained by Foulds and Mann (1978), confirmed in these experiments, are so remarkable that it seems advisable to consider all possible sources of error. The most obvious possible source is the process of dissecting the gut from the body tissues. If labelled detritus were passed to a gut diverticulum and if that diverticulum normally broke away from the gut and was counted in the body tissues, that would be an explanation for the high body counts after only $30 \mathrm{~min}$ feeding on labelled food. This possibility can be discounted for 2 reasons: (i) there is no reason to suppose that antimicrobial substances would decrease the counts if they arose from this cause; (ii) as previously stated, the variance within treatments was of the order of $10 \%$, but would be expected to be much higher if the results arose from breaking of the gut with subsequent spillage of contents. Joan Friesen (unpubl.) has confirmed that the gut normally separates cleanly from the body tissue with all its diverticula intact.

Other possible sources of error include uptake of counts in the body tissue in soluble form through the outer surface, or uptake by microorganisms attached to the body surface. These were discounted by the experimental procedures: counts were very low in the bodies of Mysis stenolepis exposed to liquid from which labelled particles had been filtered, and were very low in all mysids killed by squeezing their heads. Clearly, uptake of ${ }^{14} \mathrm{C}$ was dependent on the active feeding process.

The results show clearly that the capacity to assimilate ${ }^{14} \mathrm{C}$ cellulose is reduced to near zero levels upon sterilization with antimicrobial solution, but is restored to something close to former levels when the test animals are allowed to feed on freshly homogenized mysid guts. The obvious inference is that the mysids digest cellulose with the assistance of a gut flora, and that this flora is inhibited by holding the test animals in antimicrobial solution for $24 \mathrm{~h}$. There is, however, 
an alternative explanation that cannot be eliminated, namely that the mysids digest the cellulose with cellulase which they themselves have produced, and that the production of this enzyme is temporarily inhibited by the antimicrobial solution. Some support for this alternative is given by the fact that ${ }^{14} \mathrm{C}$ uptake by sterile mysids, while low, was not reduced to zero. On the other hand, if this explanation were true, it would be difficult to understand why re-inoculation with nonsterile mysid guts should be such a powerful factor in restoring the ability to digest cellulose. The observation that a previous diet of cellulose enhances the ability to digest cellulose, when compared with results obtained after a diet of chopped shrimp, can also be interpreted in 2 ways: either the previous diet caused a build-up of the population of microorganisms responsible for cellulose digestion, or it caused the mysids themselves to enhance their production of cellulase.

Results obtained by other investigators have in many cases been inconclusive regarding the question of whether the cellulose-digesting capabilities of aquatic invertebrates are attributable to a microflora or to the animals' own enzymes. Monk (1977) showed that gut extracts from the freshwater Gammarus pulex hydrolyzed cellulose, but he failed to isolate bacteria from those extracts. Boyle and Mitchell (1978) documented that whereas the hind guts of wood-eating termites were lined with a diverse and abundant microbial flora, 2 species of the wood-boring isopod Limnoria and the amphiphod Chelura terebrans which lives in the Limnoria burrows, all maintained a gut completely free of microorganisms. On the other hand, Wildish and Poole (1970) and Halcrow (1971) reported a reduction in cellulase activity after amphipods had been exposed to antimicrobial solutions.

Fong and Mann (1980) found that when the sea urchin Strongylocentrotus droebachiensis was induced to feed on labelled cellulose particles the label appeared in the gonads. Hence, evidence is accumulating that the ability to digest cellulose is more widespread among aquatic invertebrates than was once supposed. However, as Boyle and Mitchell (1978) pointed out, we must avoid too hasty generalizations about the property being conferred by a microbial population in the gut. In the case of Mysis stenolepis the evidence certainly points in that direction, but is not conclusive.

Acknowledgements. Thanks are due to Drs. J. A. Novitsky and L. C. Vining for helpful advice on techniques, to Dr. D. G. Patriquin for constructive criticism, and to Messrs. S. F. Watts, T. Hackney and T. Collins for practical help in the field.

\section{LITERATURE CITED}

Boyle, P. J., Mitchell, R. (1978). Absence of microorganisms in crustacean digestive tracts. Science, N.Y. 200: 1157-1159

Briggs, K. B., Tenore, K. R., Hanson, R. B. (1979). The role of microfauna in detrital utilization by the polychaete Nereis succinea (Frey and Leuckart). J. exp. mar. Biol. Ecol. 36: 225-234

Cundell, A. M., Brown, M. S., Stanford, R., Mitchell, R. (1979). Microbial degradation of Rhizophora mangle leaves immersed in the sea. Estuar. coast. mar. Sci. 9: 281-286

Elyakova, L. A. (1972). Distribution of cellulases and chitinases in marine invertebrates. Comp. Biochem. Physiol. 13B: $67-70$

Fong, W., Mann, K. H (1980). Role of gut flora in the transfer of amino acids through a marine food chain. Can. J. Fish. Aquat. Sci. 37: 88-96

Foulds, J. B. (1977). Marine mysids in detritus food chains. Ph. D. thesis, Dalhousie University, Halifax, Canada

Foulds, J. B., Mann, K. H. (1978). Cellulose digestion in Mysis stenolepis and its ecological implications. Limnol. Oceanogr. 23: 760-766

Halcrow, K. (1971). Cellulase activity in Gammarus oceanicus Segerstrale (Amphipoda). Crustaceana 20: 121-124

Monk, D. C. (1977). The digestion of cellulose and other dietary components and the $\mathrm{pH}$ of the gut in the amphipod Gammarus pulex (L.) Freshwat. Biol. 7: 28-37

Wainwright, P. F. (1977). Observations on the cellulose digestion of a marine detritivore, Mysis stenolepis. Honours thesis, Dalhousie University, Halifax, Canada

Wildish, D. J., Poole, N. J. (1970). Cellulase activity in Orchestia gammarella (Pallas). Comp. Biochem. Physiol. 33: $713-716$ 